\title{
Biological Evaluation of Tissue-Engineered Cartilage Using Thermoresponsive Poly( $N$-isopropylacrylamide)-Grafted Hyaluronan
}

\author{
Kazuaki Muramatsu, Mika Ide, Fujio Miyawaki \\ Division of Life Science and Engineering, School of Science and Engineering, Tokyo Denki University, Saitama, Japan. \\ Email: k-muramatsu@mail.dendai.ac.jp
}

Received September $28^{\text {th }}, 2011$; revised November $29^{\text {th }}, 2011$; accepted December $14^{\text {th }}, 2011$

\begin{abstract}
In order to contribute to the development of minimally invasive surgery techniques for autologous chondrocyte implantation, a novel self-assembling biomaterial consisting of thermoresponsive poly(N-isopropylacrylamide)-grafted hyaluronan (PNIPAAm-g-HA) has been synthesized as an injectable scaffold for cartilage tissue engineering. The aim of this study was to investigate the efficacy and cytocompatibility of PNIPAAm-g-HA to normal chondrocytes by using reverse transcription-polymerase chain reaction (RT-PCR) analysis and histochemical staining in preliminary in vitro and in vivo experiments. Hematoxylin and eosin staining showed homogeneous distribution of cells in the PNIPAAm-g-HA hydrogel in 3-dimensional in vitro cultivation. Alcian blue staining also indicated that abundant extracellular matrix formation, including acidic glycosaminoglycans, occurred in tissue-engineered cartilage over time in vitro. Cartilagerelated gene expression patterns, which were tested in rabbit normal chondrocytes embedded in the hydrogel, were almost maintained for 4 weeks. Transforming growth factor- $\beta 1$ (TGF- $\beta 1$ ) stimulation enhanced the expression of SRY-related HMG box-containing gene 9 (Sox9) and type X collagen genes suggesting promotion of chondrogenic differentiation. Histochemical evaluation showed neocartilage formation following subcutaneous implantation of the chondrocyte-gel mixture in nude mice. Furthermore, TGF- $\beta 1$ stimulation promoted production and maturation of the extracellular matrix of the in situ tissue engineered hyaline cartilage. These data suggested that PNIPAAm-g-HA could be a promising biomaterial, i.e., a self-assembling and injectable scaffold for cartilage tissue engineering.
\end{abstract}

Keywords: Cartilage Tissue Engineering; Hyaluronan; Self-Assembly; Thermally Responsive Material

\section{Introduction}

Articular cartilage is a specialized connective tissue, known as hyaline cartilage, consisting of chondrocytes and abundant extracellular matrix. It is mainly composed of type II collagen, hyaluronan, and proteoglycans, including sulfated-polysaccharides, and these components contribute to the specific biorheological characteristics. However, absence of blood, a lymphatic vascular system, and a nervous system cause poor repair and regeneration capability of partially injured cartilage. In the past 20 years, autologous chondrocyte implantation (ACI) techniques using cultivated chondrocytes (cell suspensions or tissue-engineered constructs) have been developed, progressed, and achieved clinical application, and are expected to be promising methods to repair and regenerate damaged cartilage [1-5]. In order to prepare tissue-engineered cartilage as implants in vitro, various bioabsorbable materials, which were formed as gels, porous, or fibers, have been used for 3-dimensional scaffolds to support and maintain the geometric shape of the constructs and to maintain the chondrocyte phenotype $[3,4$, 6-10]. Transplanted tissue-engineered cartilages are generally covered by a sutured periosteal flap to fix them at the defect site in conventional ACI procedures. To improve the issues of conventional ACI, advanced cartilage tissue engineering and regenerative medicine techniques have been newly proposed to introduce the concept of minimally invasive surgery using a microscope without taking parts of the periosteum from the proximal tibia and attempted combination with functional biomaterials, including self-assembling materials, in vitro or in vivo animal models [11-14]. In particular, utilization of poly ( $N$-isopropylacrylamide) (PNIPAAm)-conjugated copolymers as self-assembling biomaterials is thought to be an attractive strategy in terms of easily occurring thermoresponsive in situ gelation, which allows encapsulation of cells of various shapes. In addition, PNIPAAm could 
serve as reversible cell-attachment/detachment matrix for cell-sheet engineering $[15,16]$ in tissue engineering applications. Several authors reported the biocompatibility and efficacy of these copolymers for meniscus and cartilage tissue engineering $[17,18]$.

Hyaluronan (HA) is a major glycosaminoglycan consisting of repeated units of D-glucuronic acid and $\mathrm{N}$ acetyl-D-glucosamine. HA is synthesized by endogenous HA synthases (HASs) that are localized on cellular plasma membranes in cartilage and other soft-connective tissues in mammals. HA affects the physicochemical properties of extracellular matrix as well as biological functions, including cell adhesion, migration, proliferation, and even bioactive signaling. Each induced bioactivity is thought to differ with regard to the molecular size of HA and its target cells. For example, interleukin $1 \alpha(\mathrm{IL} 1 \alpha)$-induced expression of a disintegrin and metalloproteinase with thrombospondin motifs-4 (ADAMTS4) causes aggrecan degradation, which was significantly reduced by treatment of cultivated chondrocytes with high-molecular-weight HA (high-MW HA) [19]. This biological function of HA was thought to result from binding to several HA receptors such as CD44 and intracellular cell adhesion molecule 1 (ICAM1) on the cell surface. Because some intracellular signaling pathway changes due to HA via CD44 activation have been investigated [19-21], biomaterials composed of HA derivatives are expected to be bioactive scaffolds for cartilage tissue engineering.

In the present study, we developed PNIPAAm-grafted HA (PNIPAAm-g-HA) (Figure 1) as an injectable scaffold for cartilage tissue engineering. We investigated the biological efficacy of PNIPAAm-g-HA hydrogels on neocartilage formation in preliminary in vitro and in vivo experiments.

\section{Materials and Methods}

\subsection{Chemicals}

$\mathrm{N}$-isopropylacrylamide (NIPAAm), 2-aminoethanethiol hydrochloride (AET-HCl), and 2,2'-azobis(isobutyronitrile) (AIBN) were purchased from Tokyo Kasei Kogyo Co., Ltd. (Tokyo, Japan) and used as received. 1-Ethyl-3-(3-dimethylaminopropyl) carbodiimide hydrochloride (EDAC) was purchased from DOJINDO Laboratories (Kumamoto, Japan). Other high purity-grade reagents for chemical synthesis were purchased from Wako Pure Chemical Industries, Ltd. (Osaka, Japan).

\subsection{Preparation of PNIPAAm-g-HA}

Amino-terminated PNIPAAm (PNIPAAm- $\mathrm{NH}_{2}$ ) was prepared by radical polymerization using AIBN as an initiator. NIPAAm monomer $\left(1.0 \times 10^{-2} \mathrm{~mol}\right)$, AIBN $(1.0 \times$ $\left.10^{-5} \mathrm{~mol}\right)$, and AET-HCl $\left(1.0 \times 10^{-4} \mathrm{~mol}\right)$ were dissolved in degassed dimethylformamide (DMF) under argon atmosphere, and the polymerization was conducted for $6 \mathrm{~h}$ at $70^{\circ} \mathrm{C}$. The product was precipitated in excess diethyl ether and dried under reduced pressure. Then, the precipitate was dissolved in ultrapure water, dialyzed using spectra/Por 7(molecular weight cutoff [MWCO], 8000) for $48 \mathrm{~h}$ against excess ultrapure water, and then lyophilized. Graft-polymerizations of PNIPAAm- $\mathrm{NH}_{2}$ (weightaverage molecular weight $[\mathrm{Mw}]$, approximately $3.2 \times 10^{4}$ Da) to HA were carried out using water-soluble carbodiimide in phosphate buffer. Hyaluronic acid sodium salt $\left(100 \mathrm{mg}, \mathrm{Mw}\right.$, approximately $\left.7.7 \times 10^{5} \mathrm{Da}\right)$ and PNIPAAm- $\mathrm{NH}_{2}(500 \mathrm{mg})$ were dissolved in $0.05 \mathrm{M}$ phosphate buffered saline (PBS, pH 6.0) and EDAC was then added to the solution. The reaction was conducted at $24^{\circ} \mathrm{C}$ with stirring for $24 \mathrm{~h}$. To remove impurity and nonreacted PNIPAAm- $\mathrm{NH}_{2}$, the reaction mixture was dialyzed using spectra/Por 7 (MWCO, 25,000) for $48 \mathrm{~h}$ against excess ultrapure water, and then lyophilized. The synthesized PNIPAAm-g-HA was rinsed with excess acetone and precipitates were lyophilized, dried, and stored at room temperature in a desiccator.

\subsection{Fourier-Transform Infrared Analysis}

Each sample was mixed with potassium bromide powder

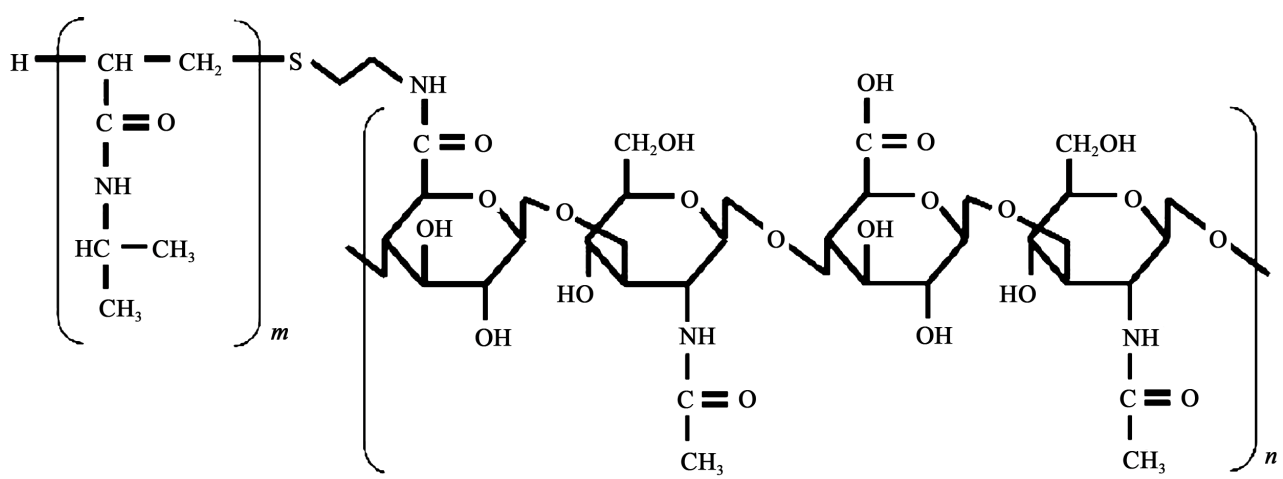

Figure 1. The chemical structure of poly( $N$-isopropylacrylamide)-grafted hyaluronan (PNIPAAm-g-HA). 
and compressed into pellets for Fourier-transform infrared (FT-IR) analysis. FT-IR spectra of samples were recorded using a model FT/IR 620 spectrometer (JASCO, Tokyo, Japan). For each spectrum obtained, a total of 68 scans were accumulated at $1 \mathrm{~cm}^{-1}$ resolution of a range between 700 and $4000 \mathrm{~cm}^{-1}$.

\subsection{Low Critical Solution Temperature Measurements}

The optical transmittance of each polymer in deionized water was measured at $500 \mathrm{~nm}$ at temperatures from $25^{\circ} \mathrm{C}$ to $45^{\circ} \mathrm{C}$ with a V-630BIO spectrophotometer (JASCO) to estimate the phase transition temperature of the specimens. The low critical solution temperature (LCST) of the polymer solution was determined from the temperature at which the solution turbidity was half of the difference between the maximum and the minimum value, as previously reported [17].

\subsection{Isolation and Cell Culture of Chondrocytes}

All animal experiments in this study were approved by the Animal Care Committee at Tokyo Denki University. Rabbit normal chondrocytes were isolated from costal cartilages by enzyme digestion. Briefly, after anesthesia with nembutal, hyaline cartilages were separated from the ribs of 6- to 7-week-old male New Zealand white rabbits, cut into 1- to 2-mm-thick pieces, and incubated in PBS containing $0.1 \%$ trypsin at $37^{\circ} \mathrm{C}$ for $1 \mathrm{~h}$ with gentle agitation. Then, cartilage pieces were rinsed 3 times with $\mathrm{Ca}^{2+}$ - and $\mathrm{Mg}^{2+}$-free PBS and digested at $37^{\circ} \mathrm{C}$ for 6 $\mathrm{h}$ in DMEM/F12 containing $2.5 \%$ collagenase or collagenase/dispase with gentle agitation. Digested cells were passed through a $100 \mu \mathrm{m}$-mesh cell strainer, collected by centrifugation, and suspended in fresh DMEM/F12 medium containing $10 \%$ fetal bovine serum (FBS), ITS (10 $\mu \mathrm{g} / \mathrm{mL}$ insulin, $6.7 \mathrm{ng} / \mathrm{mL}$ transferring, $5.5 \mu \mathrm{g} / \mathrm{mL}$ selenium), $100 \mathrm{U} / \mathrm{mL}$ penicillin $\mathrm{G}$, and $100 \mu \mathrm{g} / \mathrm{mL}$ streptomycin. After primary culture, cells were used for in vitro and in vivo experiments.

\subsection{Three-Dimensional Culture}

Chondrocytes were mixed with $1 \mathrm{wt} \%$ PNIPAAm-g-HA $\left(5.0 \times 10^{5}\right.$ cells $/ \mathrm{mL}$ in $100 \mu \mathrm{L}$ of hydrogel) and preincubated without culture medium at $37^{\circ} \mathrm{C}$ for a few minutes in centrifugal microtubes to embed the cells into PNIPAAm-g-HA hydrogels. Then, warmed culture medium was added to the tubes. The cells embedded in hydrogels were cultivated in the absence or presence of $10 \mathrm{ng} / \mathrm{mL}$ transforming growth factor- $\beta 1$ (TGF- $\beta 1$ ) by continuous exposure for 2 and 4 weeks at $37^{\circ} \mathrm{C}$ with $5 \% \mathrm{CO}_{2}$. With regard to chondrocyte differentiation in 3-dimensional cultures, the pellets of cell aggregates $\left(5.0 \times 10^{5}\right.$ cells $)$ obtained by centrifugation were also cultivated for the same periods. Three different experiments were carried out to confirm reproducibility of results.

\subsection{Nude Mouse Implantation}

PNIPAAm-g-HA hydrogel (1.5 mg gel in $150 \mu \mathrm{L}$ saline) mixed with chondrocytes $\left(5.0 \times 10^{5}\right.$ cells $)$ in the presence or absence of $10 \mathrm{ng} / \mathrm{mL}$ TGF- $\beta 1$ were transplanted by subcutaneous injection into the backs of 4-week-old male $\mathrm{BALB} / \mathrm{cA}$ Jcl-nu/nu nude mice, which were purchased from Clea (Tokyo, Japan). At 2 weeks after implantation, the mice were killed ( $\mathrm{n}=3$ for each period) using an overdose injection of nembutal, and the skin, including the implanted site $(15 \times 15 \mathrm{~mm}$ area $)$, was removed for histological evaluation.

\subsection{Reverse Transcription-Polymerase Chain Reaction}

Total RNA was extracted from cells using ISOGEN RNA isolation kit (Nippon Gene, Tokyo, Japan) with DNase I treatment according to the manufacturer's instruction. Five hundred nanogram of each RNA sample was reverse-transcribed into cDNA using SuperScript II firststrand synthesis system for RT-PCR (Invitrogen). To analyze the expression of specific genes, equal amounts of first strand cDNA were amplified by PCR using Ex Taq polymerase (Takara, Japan) and specific forward and reverse primers for each gene (Table 1). The PCR conditions were $1 \mathrm{~min}$ at $94^{\circ} \mathrm{C}, 30 \mathrm{~s}$ at $55^{\circ} \mathrm{C}$, and $1 \mathrm{~min}$ at $72^{\circ} \mathrm{C}$ for 28 to 34 cycles. The products amplified by PCR were subjected to electrophoresis in a $2.0 \%$ agarose gel, and digital photographs of ethidium bromide stained gels were taken by ImageQuant LAS4000 image analyzer (GE Healthcare).

Table 1. Primers used in PCR amplification reactions.

\begin{tabular}{lllc}
\hline Gene & & Sequence $\left(5^{\prime} \rightarrow 3^{\prime}\right)$ & $\begin{array}{c}\text { Product } \\
\text { size }(\mathrm{bp})\end{array}$ \\
\hline Sox9 & (F) & GAGCGAAGAGGACAAGTTC & 333 \\
& (R) & TACTTGTAGTCCGGGTGGT & \\
Aggrecan & (F) & GGTGTTGTGTCCACTATCG & 281 \\
& (R) & ACACGTCATAGGTCTCGTTG & \\
Col-2a1 & (F) & GACATTGGAGGGGCACCCATG & 366 \\
& (R) & GACACGGAGTAGCACCATCG & \\
Col-10a & (F) & TCATGCCCGATGACTTTACA & 397 \\
& (R) & AGCCACACCTGGTCATTTC & \\
CD44 & (F) & CCACGTGGAGAAAAATGGTC & 157 \\
& (R) & CACGTGCCCTTCTATGAACC & \\
$\beta$-actin & (F) & TGCTTCTAGGCGGACTGTTA & 314 \\
& (R) & CGTCACATGGCATCTCACGA & \\
\hline
\end{tabular}




\subsection{Histochemistry}

For cytochemical and histological analyses, specimens were fixed in $4 \%$ paraformaldehyde solution and dehydrated in $70 \%$ to $100 \%$ ethanol and xylene. Specimens were then embedded in paraffin and cut into 5- $\mu$ m-thick sections using a microtome. After dewaxing according to standard procedures, sections (i.e., nucleus and cytoplasm) were stained with hematoxylin and eosin (H \& E). Sections were also stained with alcian blue or toluidine blue solution to detect acidic polysaccharides and observed by using a DX51 microscope equipped with a DP52 digital camera system (Olympus, Japan).

\section{Results}

\subsection{Characterization of PNIPAAm-g-HA}

The structure of PNIPAAm-g-HA was characterized by FT-IR (Figure 2). PNIPAAm-g-HA had characteristic absorbance at around 2974, 1647, and $1543 \mathrm{~cm}^{-1}$ attributable to $-\mathrm{CH}_{3}$ stretching, amide I, and amide II bands of PNIPAAm- $\mathrm{NH}_{2}$, respectively, whereas original HA had amide I and II bands at around 1618 and $1560 \mathrm{~cm}^{-1}$, respectively, as previously reported [22]. The specific band at around $1410 \mathrm{~cm}^{-1}$ corresponding to $\mathrm{COO}^{-}$symmetric stretching was also relatively reduced in PNIPAAm-gHA compared with HA, which indicates coupling of the PNIPAAm polymer to HA.

The transmittance-temperature curve of the $0.5 \mathrm{wt} \%$ of PNIPAAm-g-HA aqueous solution is shown in Figure 3. LCST of PNIPAAm-g-HA was determined at around $32.0^{\circ} \mathrm{C}$, and was almost the same as that of the PNIPAAm- $\mathrm{NH}_{2}$ polymer alone $\left(31.2^{\circ} \mathrm{C}\right)$. PNIPAAm-g-HA had self-assembling potency at physiological temperature.

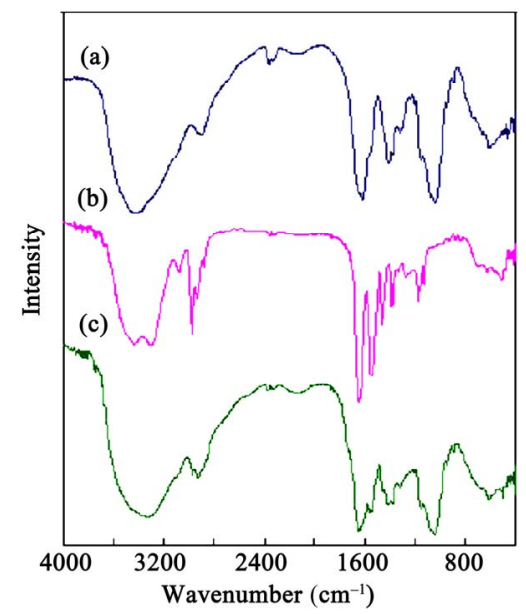

Figure 2. FT-IR spectra of (a) amino-terminated $\operatorname{poly}(\mathrm{N}$ isopropylacrylamide) (PNIPAAm- $\mathrm{NH}_{2}$ ); (b) hyaluronan (HA); and (c) PNIPAAm-g-HA.

\subsection{Extracellular Matrix Formation of the Engineered Cartilage}

The histomorphologies of in vitro tissue-engineered cartilage composed of chondrocytes embedded in PNIPAAm-g-HA hydrogel for 2 and 4 weeks are shown in Figure 4. H \& E staining revealed homogeneous distribution of chondrocytes in the tissue-engineered cartilage. Alcian blue staining also revealed production of abundant extracellular matrix, including acidic glycosaminoglycans and lacuna structure, around the cells in the hydrogel. Furthermore, extracellular matrix and engineered cartilage were hypertrophied during the culture periods.

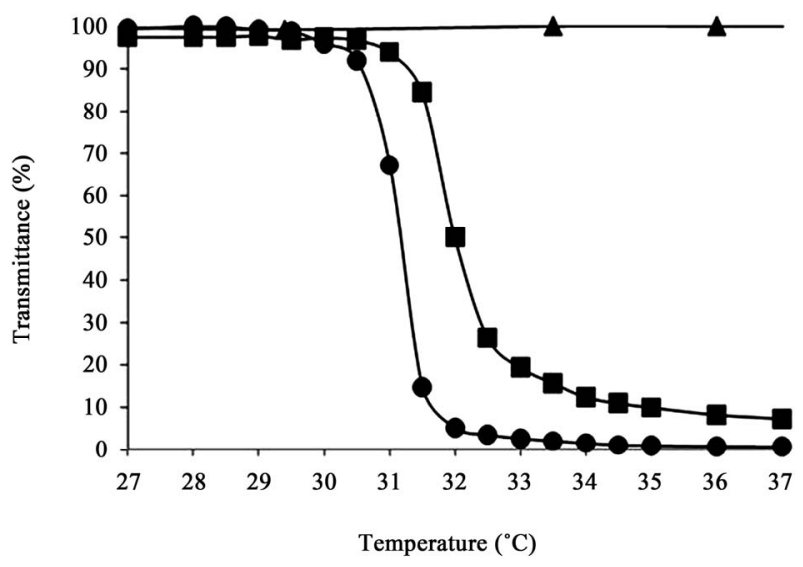

Figure 3. Thermoresponsive character of aqueous of $(\bullet)$ PNIPAAm-NH, , (A) hyaluronan, and (ø) PNIPAAm-g-HA by transmittance measurement at $500 \mathrm{~nm}$. Data are expressed as the means value of independent three measurements.
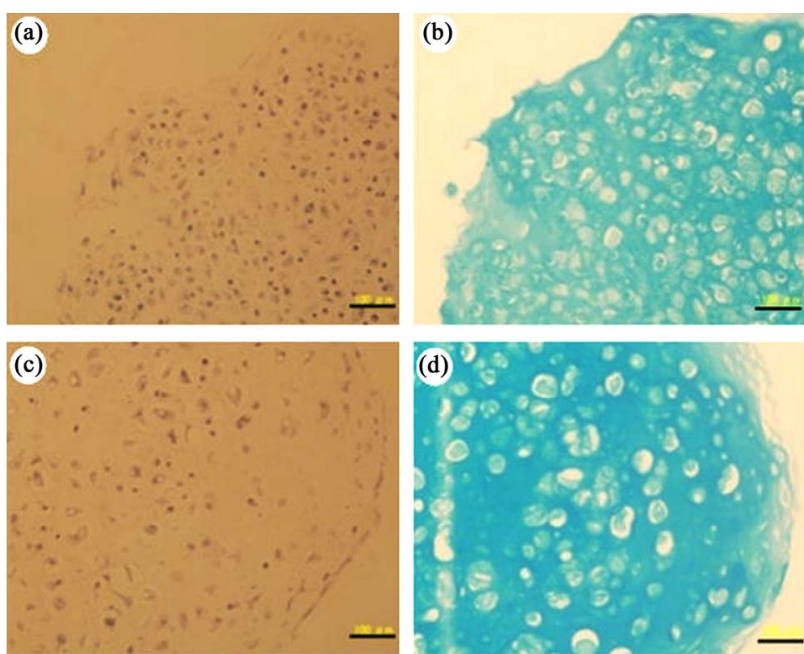

Figure 4. H \& E staining (a, c) and alcian blue staining (b, d) of PNIPAAm-g-HA hydrogel encapsulating normal chondrocytes in vitro at day $14(\mathrm{a}, \mathrm{b})$ and day $28(\mathrm{c}, \mathrm{d})$. Scale bar: $100 \mu \mathrm{m}$. 


\subsection{Gene Expressions of the Engineered Cartilage}

RT-PCR analysis using specific primers for cartilagerelated genes, including SRY-related HMG box-containing gene 9 (Sox9), aggrecan, and type II and X collagen was conducted to characterize the phenotype of chondrocytes embedded in the gel in the presence and absence of TGF- $\beta 1$ (Figure 5). The expressions of theses chondrocyte-specific genes were detected and the expression levels were maintained in the cells embedded in PHIPAAm-g-HA gel for 4 weeks. The expression of the HA receptor CD44 was also detected in the engineered cartilage. In addition, TGF- $\beta 1$-loaded hydrogel enhanced Sox 9 gene expression at day 14, and up-regulated type $\mathrm{X}$ collagen gene expression for 28 days, whereas no remarkable difference was observed in the expression of aggrecan and type II collagen.

\subsection{Neocartilage Formation in Subcutis of Nude Mice}

In order to investigate the formation of hyaline cartilage derived from transplanted rabbit chondrocytes with PNIPAAm-g-HA into subcutis of nude mice, histochemical evaluation was carried out (Figure 6). H \& E staining revealed homogeneous distribution of transplanted cells in the subcutis. Formation of chondrogenic extracellular matrix, including abundant acidic glycosaminoglycans, was investigated by alcian blue and toluidine blue staining. Round sharp cells and lacuna structure within the extracellular matrix were also observed in the neocartilage. On the other hand, no remarkable neutrophil and macrophage migration indicating continuous inflammation were observed around the neocartilage tissue in the subcutis 2 weeks after transplantation. Moreover, the addition of TGF- $\beta 1$ to PNIPAAm-g-HA hydrogel encapsulating chondrocytes resulted in hypertrophy and maturation of the chondrogenic extracellular matrix and tissue.

\section{Discussion}

Various biomaterials have been utilized as scaffolds for conventional cartilage tissue engineering [3,4,6-10]. With the introduction of microscopic surgical techniques for minimal invasion, the development of novel injectable scaffolds is still expected for advanced cartilage tissue engineering systems. Several injectable biomaterials for cartilage tissue engineering have also been studied [8-13]. However, there is no standard material for injectable biomaterial to be utilized in ACI in microscopic surgery. The purpose of this study was to evaluate the biological efficacy of PNIPAAm-g-HA developed as a novel scaffold for in situ cartilage tissue engineering, through pre

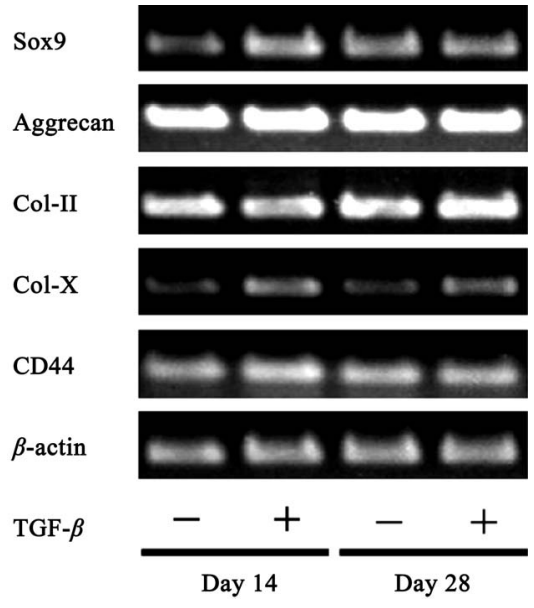

Figure 5. Expression of Cartilage-related genes in rabbit normal chondrocytes embedded in PNIPAAm-g-HA hydrogel in the presence or absence of TGF- $\beta 1$ in 3-D culture.

liminary in vitro and in vivo studies. PNIPAAm-g-HA was designed to have both characteristics of biological activity derived from high-MW HA [19-21,23,24] and in situ self-assembling potency dependent on the hydrophobic interaction with each grafted-thermoresponsive PNIPAAm chain at physiological temperature [25]. The LCST of PNIPAAm-g-HA was almost equal to that of the typical PNIPAAm polymer (Figure 3), and in situ gelation potency of transplanted PNIPAAm-g-HA via intraarticular injection was expected. We also confirmed the effect of grafted-PNIPAAm chains on lower loss modulus (G") of the HA derivative at room temperature without loss of storage modulus (G') at physiological temperature compared to original HA (data not shown).

A previous study by Matsuda and coworkers had reported that PNIPAAm-grafted HA, which was synthesized by a different method than ours, was proposed to be applied as tissue adhesion prevention material because of its non-cell-adhesive property, which was based on its behavior on bovine endothelial cells [26]. In our present study, we investigated the potency of PNIPAAm-g-HA as an injectable scaffold for cartilage tissue engineering. Chondrocytes have several HA receptors such as CD44 in plasma membrane. These receptors might contribute to the initial adhesion of cells onto PNIPAAm-g-HA molecules and favorable biological signal transduction in chondrocytes. The gene expression analysis of a previous study showed that Sox9 and aggrecan genes were upregulated in chondrocytes embedded in the PNIPAAmg-HA gel compared with those in cell aggregates, whereas type $\mathrm{X}$ collagen expression in the gel was lower than that in the aggregate (data not shown). These findings indicated that the PNIPAAm-g-HA gel was more effective for prevention of hypertrophic maturation of early staged hyaline cartilage. High-MW HA in extracellular matrix 
may be relevant for proteoglycan synthesis in cartilage. For example, since it is known that HA enhances chondroitin sulfate synthesis in chondrocytes cultivated in collagen gels [27], aggrecan, which is a major proteoglycan interacts with chondroitin sulfate in cartilage and binds to HA via a link-protein. In addition, appropriate interpenetrative-microenvironment surrounding cells in the PNIPAAm-g-HA hydrogel might improve the permeability of bioactive molecules and secreted-extra-cellular matrix accumulation resulting in chondrogenic phenotype induction.

Effects of TGF- $\beta 1$ activity on the expression of cartilage-related genes and extracellular matrix formation in chondrocytes embedded in PNIPAAm-g-HA have been investigated in vitro (Figure 5) and in vivo (Figure 6), respectively. TGF- $\beta$ regulates the expression of various genes by activation of intracellular Smad signaling pathways via type I/II TGF- $\beta$ receptors, which have serine/threonine kinase activities [28-32]. Several transcriptional activation mechanisms for target genes by Smads binding onto DNA that are relevant to TGF- $\beta$ stimulation have been reported [33-35]. The mitogen-activated protein kinase (MAPK) signaling pathway via TGF- $\beta$-activated kinase 1 (TAK1) possibly resuls in transcription factor 2 (ATF-2) activation [36,37]. In general, it is thought that TGF- $\beta /$ Smads signaling resulting in Sox9 activation enhances primary chondrogenic differentiation of mesenchymal stem cells [34] and represses chondrocyte hypertrophic differentiation $[38,39]$. However, in the present study, transient Sox9 gene expression (for 14 days) as well as continuous type $\mathrm{X}$ collagen gene expression (for 28 days) was observed in continuously TGF- $\beta 1$ stimulated cells embedded in the gel. These findings indicated that TGF- $\beta 1$ promoted multiple steps of the chondrogenic differentiation, including both primary differentiation and hypertrophic differentiation in the PNIPAAm-g-HA hydrogel, which might be possible since Sox 9 could also induce type $\mathrm{X}$ collagen expression via Runx2 activation to cooperate with BMP4 in chick chondrocytes [40].

In in vivo experiments (Figure 6), thymus-deficient nude mice were used to avoid the affect of $\mathrm{T}$ cell-dependent cellular immunity against rabbit chondrocytes to simulate autologous cell transplantation. The subcutaneously transplanted chondrocytes/PNIPAAm-g-HA mixture formed hyaline-like cartilage without signs of continuing inflammation in these mice. Since high-MW HA could contribute to moderation of inflammation of chondrocytes and other cells [19,25,41-45], PNIPAAm-g-HA might be a promising scaffold with anti-inflammatory potency. In addition, more abundant extracellular matrix formation was induced during transplantation of a mixture of chondrocytes and TGF- $\beta 1$-loaded PNIPAAmg-HA. Thus, it was confirmed that PNIPAAm-g-HA was an injectable bioactive scaffold that supports and induces the potency of chondrogenic cells and growth factors. Further studies on the effects of in situ cartilage tissue engineering on the repair of osteochondral defects using the PNIPAAm-g-HA system in a rabbit knee model are now under way.
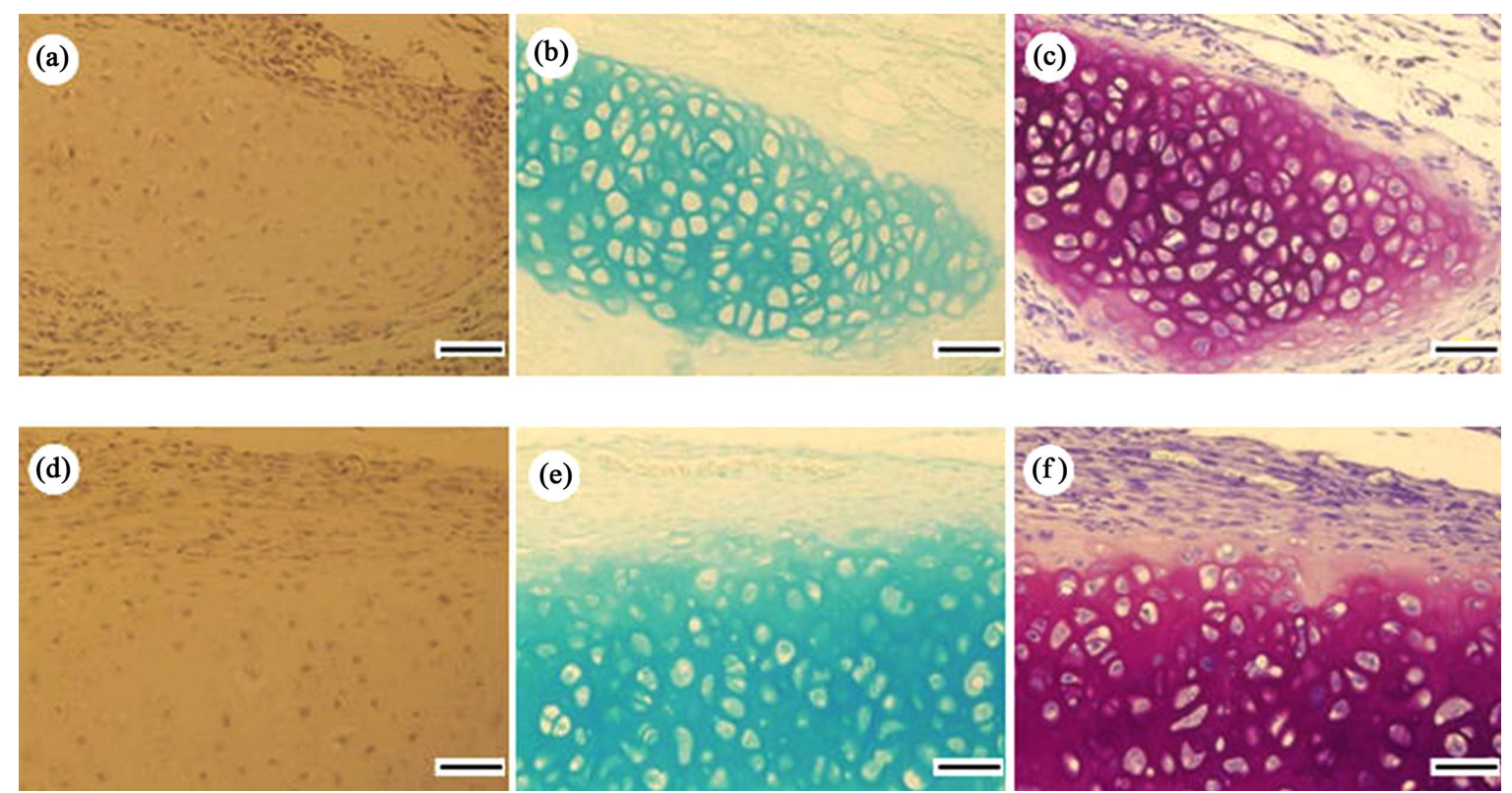

Figure 6. Histochemical staining showing in situ chondrogenesis derived from a mixture of rabbit chondrocytes and PNIPAAm-g-HA in the absence (a)-(c) or presence (d)-(f) of TGF- $\beta 1$ at 2 weeks after subcutaneous transplantation into nude mice. (a) and (d) H\&E staining; (b) and (e) Alcian blue staining; (c) and (f) Toluidine blue staining. Scale bar: $100 \mu \mathrm{m}$. 


\section{Conclusion}

In the present study, we investigated the chondrogenic potency of in situ engineered cartilage composed of a mixture of chondrocytes and PNIPAAm-g-HA, which was developed as a self-assembling and injectable biomaterial. Moreover, neocartilage formation with abundant extracellular matrix was induced by transplantation of this mixture in the presence of TGF- $\beta 1$, even in the ectopic subcutis of nude mice. Thus, although further studies are necessary, PNIPAAm-g-HA could be a promising biomaterial for in situ cartilage tissue engineering because it is a self-assembling and injectable biomaterial.

\section{Acknowledgements}

The authors thank Mr. Taichi Kato, Mr. Yuji Saito, and Ms. Nana Hiura for technical assistances. We also thank Mr. Masahiro Sekine (Saitama industrial technology center, Saitama, Japan) and Mr. Satoshi Noguchi for measurement of the rheological characteristics of the specimens. This study was partially supported by a grant of the Strategic Research Foundation Grant-aided Project for Private Universities from the Ministry of Education, Culture, Sport, Science, and Technology, Japan (MEXT), 2008-2012 (S0801023).

\section{REFERENCES}

[1] M. Brittberg, A. Lindahl, A. Nilsson, C. Ohlsson, O. Isaksson and L. Peterson, "Treatment of Deep Cartilage Defects in the Knee with Autologous Chondrocyte Transplantation," New England Journal of Medicine, Vol. 331, No. 14,1994 , pp. 889-895. doi:10.1056/NEJM199410063311401

[2] J. B. Richardson, B. Caterson, E. H. Evans, B. A. shton and S. Roberts, "Repair of Human Articular Cartilage after Implantation of Autologous Chondrocytes," Journal of Bone and Joint Surgery (Br), Vol. 81, No. 6, 1999, pp. 1064-1068. doi:10.1302/0301-620X.81B6.9343

[3] M. Ochi, Y. Uchio, K. Kawasaki, S. Wakitani and J. Iwasa, "Transplantation of Cartilage-Like Tissue Made by Tissue Engineering in the Treatment of Cartilage Defects of the Knee," Journal of Bone and Joint Surgery (Br), Vol. 84, 2002, pp. 571-578. doi:10.1302/0301-620X.84B4.11947

[4] H. Tohyama, K. Yasuda, A. Minami, T. Majima, N. Iwasaki, T. Muneta, I. Sekiya, K. Yagishita, S. Takahashi, K. Kurokouchi, Y. Uchio, J. Iwasa, M. Deie, N. Adachi, K. Sugawara and M. Ochi, "Atelocollagen-Associated Autologous Chondrocyte Implantation for the Repair of Chondral Defects of the Knee: A Prospective Multicenter Clinical Trial in Japan," Journal of Orthopedic Science, Vol. 14 , No. 5 , 2009, pp. 579-588. doi:10.1007/s00776-009-1384-1

[5] J. B. Moseley Jr., A. F. Anderson, J. E. Browne, B. R. Mandelbaum, L. J. Micheli, F. Fu and C. Erggelet, "Long-Term
Durability of Autologous Chondrocyte Implantation. A Multicenter, Observational Study in US Patients," American Journal of Sports and Medicine, Vol. 38, No. 2, 2010, pp. 238-246. doi:10.1177/0363546509348000

[6] M. Sittinger, D. Reitzel, M. Dauner, H. Hierlemann, C. Hammer, E. Kastenbauer, H. Planck, G. R. Burmester and J. Bujia, "Resorbable Polyesters in Cartilage Engineering: Affinity and Biocompatibility of Polymer Fiber Structures to Chondrocytes," Journal of Biomedical Materials Research, Vol. 33, No. 2, 1996, pp. 57-63.

doi:10.1002/(SICI)1097-4636(199622)33:2<57::AID-JB M1>3.0.CO;2-K

[7] B. Grigolo, L. Roseti, M. Fiorini, M. Fini, G. Giavaresi, N. N. Aldini, R. Giardino and A. Facchini, "Transplantation of Chondrocytes Seeded on a Hyaluronan Derivative $\left(\right.$ Hyaff $\left.^{\circledR}-11\right)$ into Cartilage Defects in Rabbits," Biomatrrials, Vol. 22, No. 17, 2001, pp. 2417-2424. doi:10.1016/S0142-9612(00)00429-4

[8] P. Brun, G. Abatangelo, M. Radice, V. Zacchi, D. Guidolin, D. D. Gordini and R. Cortivo, "Chondrocyte Aggregation and Reorganization into Three-Dimentional Scaffolds," Journal of Biomedical Materials Research, Vol. 46, No. 3, 1999, pp. 337-346. doi:10.1002/(SICI)1097-4636(19990905)46:3<337::AIDJBM5>3.0.CO;2-Q

[9] L. A. Solchage, J. E. Dennis, V. M. Goldberg and A. I. Caplan, "Hyaluronic Acid-Based Polymers as Cell Carriers for Tissue-Engineered Repair of Bone and Cartilage," Journal of Orthopedic and Research, Vol. 17, No. 2, 1999, pp. 205-213. doi:10.1002/jor.1100170209

[10] Z. Gugala and S. Gogolewski, "In Vitro Growth and Activity of Primary Chondrocytes on a Resorbable Polylactide Three-Dimentional Scaffold," Journal of Biomedical Materials Research, Vol. 49, No. 2, 2000, pp. 183-191. doi:10.1002/(SICI) 1097-4636(200002)49:2<183::AID-JB $\mathrm{M} 5>3.0 . \mathrm{CO} ; 2-\mathrm{D}$

[11] J. Kisiday, M. Jin, B. Kurz, H. Hung, S. Zhang and A. J. Grodzinsky, "Self-Assembling Peptide Hydrogel Fosters Chondrocyte Extracellular Matrix Production and Cell Division: Implications for Cartilage Tissue Repair," Proceedings of the National Academy of Science, Vol. 99, No. 15, 2002, pp. 9996-10001. doi:10.1073/pnas.142309999

[12] M. Jasionowski, K. Krzyminski, W. Chrisler, L. M. Markille, J. Morris and A. Gutowska, "Thermally-Reversible gel for 3-D Cell Culture of Chondrocytes," Journal of Materials Science: Materials in Medicine, Vol. 15, No. 5, 2004, pp. 575-582. doi:10.1023/B:JMSM.0000026379.24560.a2

[13] M. Ochi, N. Adachi, H. Nobuto, S. Yanada, Y. Ito and M. Agung, "Articular Cartilage Repair Using Tissue Engineering Technique-Novel Approach with Minimally Invasive Procedure," Artificial Organs, Vol. 28, No. 1, 2004, pp. 28-32. doi:10.1111/j.1525-1594.2004.07317.x

[14] R. C. Pereira, M. Scaranari, P. Castagnola, M. Grandizio, H. S. Azevedo, R. L. Reis, R. Cancedda and D. Gentili, "Novel Injectable Gel (System) as a Vehicle for Human Articular Chondrocytes in Cartilage Tissue Regeneration," Journal of Tissue Engineering and Regenerative Medicine, Vol. 3, No. 2, 2009, pp. 97-106. 
doi: $10.1002 /$ term. 145

[15] N. Yamada, T. Okano, H. Sakai, F. Karikusa, Y. Sawasaki and Y. Sakurai, "Thermo-Responsive Polymeric Surfaces; Control of Attachment and Detachment of Cultured Cells," Macromolecular Chemistry, Rapid Communication, Vol. 11, No. 11, 1990, pp. 571-576. doi:10.1002/marc.1990.030111109

[16] O. H. Kwon, A. Kikuchi, M. Yamato, Y. Sakurai and T. Okano, "Rapid Cell Sheet Detachment from Poly $(N$-isopropylacrylamide)-Grafted Porous Cell Culture Membranes," Journal of Biomedical Materials Research, Vol. 50, No. 1, 2000, pp. 82-89.

doi:10.1002/(SICI)1097-4636(200004)50:1<82::AID-JB $\mathrm{M} 12>3.0 . \mathrm{CO} ; 2-7$

[17] J. P. Chen and T. H. Cheng, "Thermo-Responsive Chitosan-Graft-Poly $(N$-isopropylacrylamide) Injectable Hydrogel for Cultivation of Chondrocytes and Meniscus Cells," Macromolecular Bioscience, Vol. 6, No. 12, 2006, pp. 1026-1039. doi:10.1002/mabi.200600142

[18] K. H. Park, P. D. Lee and K. Na, "Transplantation of Poly( $N$-isopropylacrylamide-co-vinylimidazole) Hydrogel Constructs Composed of Rabbit Chondrocytes and Growth Factor-Loaded Nanoparticles for Neocartilage Formation," Biotechnology Letters, Vol. 31, No. 3, 2009, pp. 337-346. doi:10.1007/s10529-008-9871-6

[19] T. Yatabe, S. Mochizuki, M. Takizawa, M. Chijiiwa, A. Okada, T. Kimura, Y. Fujita, H. Matsumoto, Y. Toyama and Y. Okada, "Hyaluronan Inhibits Expression of ADAMTS4 (Aggrecanase-1) in Human Osteoarthritic Chondrocytes," Annals of the Rheumatic Diseases, Vol. 68, No. 6, 2009, pp. 1051-1058. doi:10.1136/ard.2007.086884

[20] L. Y. W. Bourguignon, E. Gilad, K. Peyrollier, A. Brightman and R. A. Swanson, "Hyaluronan-CD44 Interaction Stimulates Rac1 Signaling and PKN $\gamma$ Kinase Activation Leading to Cytoskeleton Function and Cell Migration in Astrocytes," Journal of Neurochemistry, Vol. 101, No. 4, 2007, pp. 1002-1017. doi:10.1111/j.1471-4159.2007.04485.x

[21] R. A. Andhare, N. Takahashi, W. Knudson and C. B. Knudson, "Hyaluronan Promotes the Chondrocyte Response to BMP-7," Osteoarthritis Cartilage, Vol. 17, No. 7, 2009, pp. 906-916. doi:10.1016/j.joca.2008.12.007

[22] M. Fuente, B. Seijo and M. J. Alonso, "Novel Hyaluronan-Based Nanocarriers for Transmucosal Delivery of Macromolecules," Macromolecular Bioscience, Vol. 8, No. 5, 2008, pp. 441-450. doi:10.1002/mabi.200700190

[23] C. B. Knudson, "Hyaluronan and CD44: Strategic Players for Cell-Matrix Interactions during Chondrogenesis and Matrix Assembly," Birth Defects Research (Part C), Vol. 69 , No. 2, 2003, pp. 174-196.

[24] G. Lisignoli, S. Cristino, A. Piacentini, C. Cavallo, A. J. Caplan and A. Facchini, "Hyaluronan-Based Polymer Scaffold Modulates the Expression of Inflammatory and Degradative Factors in Mesenchymal Stem Cells: Involvement of Cd44 and Cd54," Journal of Cellular Physiology, Vol. 207, No. 2, 2006, pp. 364-373. doi:10.1002/jep.20572

[25] Y. Hirose, T. Amiya, Y. Hirokawa and T. Tanaka, "Phase
Transition of Submicron Gel Beads," Macromolecules, Vol. 20, No. 6, 1987, pp. 1342-1344. doi: $10.1021 / \mathrm{ma} 00172 \mathrm{a} 029$

[26] S. Ohya, Y. Nakayama and T. Matsuda, "Thermoresponsive Artificial Extracellular Matrix for Tissue Engineering: Hyaluronic Acid Bioconjugated with Poly( $N$-isopropylacrylamide) Grafts," Biomacromolecules, Vol. 2, No. 3, 2001, pp. 856-963. doi:10.1021/bm010040a

[27] K. Kawasaki, M. Ochi, Y. Uchio, N. Adachi and M. Matsusaki, "Hyaluronic Acid Enhances Proliferation and Chondroitin Sulfate Synthesis in Cultured Chondrocytes Embedded in Collagen Gels," Journal of Cellular Physiology, Vol. 179, No. 2, 1999, pp. 142-148. doi:10.1002/(SICI)1097-4652(199905)179:2<142::AID-J CP4>3.0.CO;2-Q

[28] P. Franzen, P. ten Dijke, H. Ichijo, H. Yamashita, P. Schulz, C. H. Heldin and K. Miyazono, "Cloning a TGF Beta Type I Receptor That Forms a Heteromeric Complex with the TGF Beta Type II Receptor," Cell, Vol. 75, No. 4, 1993, pp. 681-692. doi:10.1016/0092-8674(93)90489-D

[29] G. Lagna, A. Hata, A. Hemmati-Brivanlou and J. Massague, "Partnership between DPC4 and SMAD Proteins in TGF- $\beta$ Signaling Pathways," Letters to Nature, Vol. 383, 1996, pp. 832-836. doi:10.1038/383832a0

[30] Y. Zhang, X. H. Feng, R. Y. Wu and R. Derynck, "Receptor-Associated Mad Homologues Synergize as Effectors of the TGF- $\beta$ Response," Letters to Nature, Vol. 383, 1996, pp. 168-172. doi:10.1038/383168a0

[31] J. Massaous and A. Hata, "TGF-Beta Signaling through the Smad Pathway," Trends in Cell Biology, Vol. 7, No. 5, 1997, pp. 187-192. doi:10.1016/S0962-8924(97)01036-2

[32] A. Nakao, M. Afrakhte, A. Moren, T. Nakayama, J. L. Christian, R. Heuchel, S. Itoh, M. Kawabata, N. E. Heldin, C. H. Heldin and P. T. Dijke, "Identification of Smad 7, a TGF $\beta$-Inducible Antagonist of TGF- $\beta$ Signaling," Nature, Vol. 389, No. 6651, 1997, pp. 631-635.

[33] K. Johnson, H. Kirkpatrick, A. Comer, F. M. Hoffmann and A. Laughon, "Interaction of Smad Complexes with Tripartite DNA-Binding Sites," Journal of Biological Chemistry, Vol. 274, No. 29, 1999, pp. 20709-20716. doi:10.1074/jbc.274.29.20709

[34] T. Furumatsu, M. Tsuda, N. Taniguchi, Y. Tajima and H. Asahara, "Smad3 Induces Chindrogenesis through the Activation of SOX9 via CREB-Binding Protein/p300 Recruitment," Journal of Biological Chemistry, Vol. 280, No. 9, 2005, pp. 8343-8350. doi:10.1074/jbc.M413913200

[35] P. Makkar, P. R. M. Metpally, S. Sangadara and B. V. B. Reddy, "Modeling and Analysis of MH1 Domain of Smads and Their Interaction with Promoter DNA Sequence Motif," Journal of Molecular Graphics \& Modeling, Vol. 27, No. 7, 2009, pp. 803-812. doi:10.1016/j.jmgm.2008.12.003

[36] B. Qiao, S. R. Padilla and P. D. Benya, "Transforming Growth Factor (TGF)- $\beta$-Activated Kinase 1 Mimics and Mediates TGF- $\beta$-Induced Stimulation of Type II Collagen Synthesis in Chondrocytes Independent of Col2al Tran- 
scription and Smad3 Signaling," Journal of Biological Chemistry, Vol. 280, No. 17, 2005, pp. 17562-17571. doi:10.1074/jbc.M500646200

[37] L. M. Gunnell, J. H. Jonason, A. E. Loiselle, A. Kohn, E. M. Schwarz, M. J. Hilton and R. J. O'keefe, "TAK1 Regulates Cartilage and Joint Development via the MAPK and BMP Signaling Pathways," Journal of Bone and Mineral Research, Vol. 25, No. 8, 2010, pp. 1784-1797. doi:10.1002/jbmr.79

[38] C. M. Ferguson, E. M. Schwarz, P. R. Reynolds, J. E. Puzas, R. N. Rosier and R. J. O'keefe, "Smad2 and 3 Mediate Transforming Growth Factor- $\beta 1$-Induced Inhibition of Chondrocyte Maturation," Endocrinology, Vol. 141, No. 12,2000 , pp. $4728-4735$. doi:10.1210/en.141.12.4728

[39] X. Yang, L. Chen, X. Xu, C. Li, C. Huang and C. X. Deng, "TGF- $\beta /$ Smad3 Signals Repress Chondrocyte Hypertrophic Differentiation and Are Required for Maintaining Articular Cartilage," Journal of Cellular Biology, Vol. 153, No. 1, 2001, pp. 35-46. doi:10.1083/jcb.153.1.35

[40] H. Kempf, A. Ionescu, A. M. Udager and A. B. Lassar, "Prochondrogenic Signals Induce a Competence for Runx2 to Activate Hypertrophic Chondrocyte Gene Expression," Developmental Dynamics, Vol. 236, No. 7, 2007, pp. 19541962. doi: $10.1002 /$ dvdy. 21205

[41] D. Presti and J. E. Scott, "Hyaluronan-Mediated Protective Effect against Cell Damage Caused by Enzymatically
Produced Hydroxyl (OH-) Radicals Is Dependent on Hyaluronan Molecular Mass," Cell Biochemistry and Function, Vol. 12, No. 4, 1994, pp. 281-288. doi:10.1002/cbf.290120409

[42] K. S. Santangelo, A. L. Johnson, A. S. Ruppert and A. L. Bertone, "Effects of Hyaluronan Treatment on Lipopolysaccharide-Challenged Fibroblast-Like Synovial Cells," Arthritis Research \& Therapy, Vol. 9, No. 1, 2007, pp. R1-R11. doi:10.1186/ar2104

[43] Y. Y. Liu, C. H. Lee, R. Dedaj, H. Zhao, H. Mrabat, A. Sheidlin, O. Syrkina, P. M. Huang, H. G. Garg, C. A. Hales and D. A. Quinn, "High-Molecular-Weight Hyaluronan-A Possible New Treatment for Sepsis-Induced Lung Injury: A Preclinical Study in Mechanically Ventilated Rats," Critical Care, Vol. 12, No. 4, 2008, pp. R102-R112. doi:10.1186/cc6982

[44] T. Pauloin, M. Dutot, F. Joly, J. M. Warnet and P. Rat, "High Molecular Weight Hyaluronan Decreases UVBInduced Apotosis and Inflammation in Human Epithelial Corneal Cells," Molecular Vision, Vol. 15, 2009, pp. 577 583.

[45] G. M. Campo, A. Avenoso, S. Campo, A. D. Ascola, P. Traina, C. A. Rugolo and A. Calatroni, "Differential Effects of Molecular Mass Hyaluronan on Lipopolysaccharide-Induced Damage in Chondrocytes," Innate Immunity, Vol. 16, No. 1, 2010, pp. 48-63. doi:10.1177/1753425909340419 